\title{
Hygienic Ranking of Coal Dust by Biological Effects in the Inhalation Experiment
}

\author{
Lutsenko LA*1 and Gvozdeva LL ${ }^{2}$ \\ ${ }^{1}$ F.F. Erisman Federal scientific center of hygiene, Moscow region, Russia \\ ${ }^{2}$ F.F. Erisman Federal scientific center of hygiene, Moscow region, Russia
}

*Corresponding author: Lutsenko Lydia Alexandrovna, Department of occupational medicine, Federal Budgetary Institution of Science "Federal Scientific Center of Hygiene named after F Erisman" Federal Service for the Protection of Consumer Rights and Human Welfare, head of the, Doctor of Medical Sciences, Russia

\begin{tabular}{|c|c|}
\hline ARTICLE INFO & ABSTRACT \\
\hline $\begin{array}{l}\text { Received: 蔧 March 07, } 2019 \\
\text { Published: 蔧 March 18, } 2019\end{array}$ & $\begin{array}{l}\text { Citation: Lutsenko LA, Gvozdeva LL. Hygienic Ranking of Coal Dust by Biological Effects } \\
\text { in the Inhalation Experiment. Biomed I Sci \& Tech Res 16(1)-2019. BISTR. MS.ID.002794. }\end{array}$ \\
\hline
\end{tabular}

\section{Introduction}

Modern methodology for managing the risk of occupational diseases of dust etiology is implemented in the form of monitoring compliance with the hygienic regulations of industrial aerosols and proposals for regulating dust exposure doses, as a measure of "protection by time" [1]. At the same time, high rates of dust occupational diseases among coal industry workers require improving the strategy of hygienic dust hazard management. impact based primarily on clinical and hygienic data on the health status of workers, but also on a broader use of the results of an experiment to assess the biological effects of dust from fossil coal. Within the framework of the above tasks, we analyzed the results of an inhalation experiment to assess the effect of dust of 3 types of fossil coal: anthracite of different petrographic composition (vitrinite - Avitr. And fusinite - Afyuz); coal of various degrees of sintering (energy - KUener. and Coking - Kukkoks.); brown coal: with a predominance of humic acids (BUgk) and with a higher yield of fulvic acids (BUfk) [2] All dust was low-ash with a content of free silicon dioxide $-0.14-2.18 \%$. The generated dust concentrations in the dust chambers ranged from 270 to $380 \mathrm{mg} / \mathrm{m} 3$ the dispersion of anthracite dust (by mass of the fine fraction measured by a twostage gravimetry instrument) was $25 \%$, and brown and brown coal: $42.0-59.6 \%$.
Considering the existing hypotheses of the pathogenesis of anthracosis, which give an important role to the participation of free-radical processes in the mechanism of the fibro genic effect of inhaled dust $[3,4]$ and differentiated grouping biological indicators studied in a chronic inhalation experiment. At the same time, 4 effects are highlighted in the reaction of the bronchopulmonary system. The first, fibro genic, was characterized by a cell proliferative reaction, the duration of the profibrotic stage, the development of connective tissue fibers, an increase in the mass of dry lungs, lipids, the absolute content of total oxyproline and its fractions. Second - cytotoxic - assessed by paratracheal lymph node reaction. This pathway is considered pathological, as it is activated when macrophages are rapidly and actively destroyed $[3,4]$. The third, irritating or resorptive-toxic, was evaluated by increasing the mass of the moist lung, mass coefficient, non-specific indicators of the reaction of other internal organs and systems $[5,6]$.

For the first time, we isolated a bronchogenic effect, judged by the relative content $(\mathrm{mg} / 100 \mathrm{~g}$ of tissue) of specific connective tissue proteins: elastin and collagen, since it is known that the destruction of the elastic framework of the lung underlies the development of obstructive syndrome and pulmonary emphysema [4]. We calculated the probability of the risk of different effects 
of dust on the bronchopulmonary system with respect to the boundary of the norm $(X \pm 1.64 \rrbracket)$, taking into account the accumulated frequencies for three doses of dust. At the same time, the following gradations were accepted: 1 degree of risk - close to threshold (indicators exceeded relative to control less than in $16 \%$ of experimental animals), grade 2 - the risk is poorly expressed ( 16 to $50 \%$ of animals react), grade 3 is moderately expressed ( from 50.1 to $80 \%$ ), 4th degree - strongly pronounced (over $80 \%$ of animals in the experimental group react). The severity of the effects of a biological effect in the experimental groups of animals was compared with those of the control group. We took into account the frequency of the modified indicators, both $\%$ of the sum of the examined indicators, and the intensity of the shift.

The intensity of the shift was expressed in arbitrary units equal to the sum of the normalized shifts relative to the control (in points), divided by the number of the examined parameters and multiplied by 100 . The following gradation was adopted; 1 point corresponded to the difference from the control indicators by no more than $50 \%, 2$ points - the difference was from 50 to $100 \%, 3$ points - from 101 to $200 \%, 4$ points - over $200 \%$. The ratio of the intensity of shifts under the action of various types of coal dust was designated by us as the coefficient of aggressiveness. Analysis of the results showed that during the period of inhalation of anthracite dust of different petrographic composition, the irritating effect was most active, then fibro genic followed in the frequency of shifts, and cytotoxic effect in severity. Both of them were more pronounced in Avitr dust. In the post-inhalation period, an increase in the cytotoxic effect was found in both types of anthracite dust. At the same time, the fibro genic effect was more amplified in the fusinite anthracite sample. The irritating effect disappears from Avitr dust. and weakly preserved by dust. The bronchogenic effect was almost 5 times weaker than the fibro genic and cytotoxic effect. The severity of the bronchogenic effect during the inhalation period was dominated by Aphus dust, and in the post-inhalation period, by Avitr dust. In general, changes in the largest share of indicators were poorly expressed, which was confirmed by histopathological data, and these shifts more often corresponded to 2 degrees of risk [7].

During the period of inhalation of coal dust, which differs in the degree of sintering, the probability of the risk of a fibro genic effect was higher under the effect of KUKOKS, whereas during the postinhalation period the fibro genic effect was noticeably weakened by KUENER dust. During the inhalation period, the bronchogenic effect of each of the studied samples of coal dust was weaker than fibro genic, but it is important to note that the severity of this effect remained at the same level during the post-inhalation period. Among the indicators of the reaction of the bronchopulmonary system to the effects of coal dust, the most common was the irritating effect. During the period of inhalation in frequency, it exceeds the bronchogenic, with the dust of Coener. irritating effect was stronger than fibro genic. In the postingal period, the irritant effect intensified in the dust of coking coal, whereas in the energy coagent it weakened. In general, the effect of dust Kukkoks. causes more pronounced risk of developing adverse effects from the bronchopulmonary system: the proportion of indicators corresponding to 3 and 4 degrees of risk was 2.5 times higher than that of dust KUener. (respectively $37.1 \%$ against $14.8 \%$ ).

It is important to note that during inhalation of both types of brown coal dust, a characteristic irritant effect was changed: all controlled indicators related to the irritant effect were changed; units This is followed by a fibro genic effect, the severity of which was 1.8 times stronger than the bronchogenic effect, and it turned out to be stronger in BUUK dust. For brown dust Coal with a higher content of fulvic acids, irritant and cytotoxic effects were higher compared to the effect of CMC dust. The least frequently observed samples of brown coal dust showed a weak cytotoxic effect. In the post-inhalation period, there is no progression of fibro genic and bronchogenic effects, and in both samples of brown coal dust the cytotoxic effect is weakened. Signs of irritation were more pronounced in BUGK dust and did not progress in BUUK dust. According to the final indicators of the lung tissue reaction, both types of brown coal dust are estimated almost equally. According to the results of the study, hygienic ranking of dust of fossil coal was carried out on the basis of taking into account the intensity of shifts and the dynamics of specific indicators of the impact of the accumulated dose of dust on the bronchopulmonary system. The investigated samples of coal dust are divided into 2 groups: dangerous (group 1) and less dangerous (group 2). During inhalation, the dust of group 1 fibro genic (115.2 units), cytotoxic (105.7 units) and irritant (142.2 units) effects were 1.51-2.66 times stronger than dust group, and the bronchogenic effect (53.3 units) was 4.26 times stronger.

In the postingal period of dust of group 1, the severity of all effects is preserved or weakly enhanced (up to 1.4 times), only the bronchogenic effect is weakened (1.9 times). In dust of group 2 , all effects are weakened, and especially sharply (4.6-4.8 times) bronchogenic (from 12.5 to 2.7 units) and irritating (from 89.0 to 18.3 units) effects. As a result, the difference in the action of dangerous and less dangerous dust of fossil coal increases to 5.2 - 10.2 times. According to the average values for the inhalation period, the coefficient of aggressiveness of these dust groups is 1.91; for the post-inhalation period, it increases to 4.2. Based on the set of considered biological effects, the following are classified as dangerous during the inhalation period: Kukkoks; Avitr; Afuz; BUGK, BKFK (intensity of their action -104.1 units), and in the postingalation period: Kukkoks; Avitr; Afuz. (117.1 units). Less dangerous during inhalation is dust KUener. (intensity of the action - 54.4 units), in the postintubation period - dust KUener; BUGK, BUFK. (27.9 units). Thus, the investigated coal dust was most different in the danger of progression or the intensity of the process attenuation during the post-inhalation period. It is precisely the 
consideration of the peculiarities of the dynamics of the pathological process in the respiratory organs that is important in planning and justifying the expected effectiveness of the measures of medical and biological prevention of occupational dust diseases Table 1.

Table 1: Indicators of the reaction of animals to the effects of coal dust in a chronic experiment.

\begin{tabular}{|c|c|c|c|c|c|}
\hline \multirow{2}{*}{ Duration of Experience } & \multirow{2}{*}{\multicolumn{2}{|c|}{$\begin{array}{l}\text { Group of Animals } \\
\text { Dry Lung Weight, }\end{array}$}} & \multicolumn{3}{|c|}{ Indicators } \\
\hline & & & Mg Collagen, & Elastin, Mkg\% & \\
\hline \multirow{6}{*}{ Inhalation } & \multirow{6}{*}{ Anthracite } & & $430.7 \pm 44.7 \mathrm{~h}$ & & \multirow{3}{*}{$66,0 \pm 6,7$} \\
\hline & & Avitr & $P \leq 0.01$ & $1802.7 \pm 105.0 x$ & \\
\hline & & & & $\mathrm{P} \leq 0.02$ & \\
\hline & & \multirow{2}{*}{ Affusion } & $396.7 \pm 31.7 x$ & \multirow{2}{*}{$1558.2 \pm 109,8$} & \multirow{2}{*}{$78,7 \pm 6,64$} \\
\hline & & & $\mathrm{P} \leq 0.05$ & & \\
\hline & & Control & $250.3 \pm 31.2$ & $1348.4 \pm 89.7$ & $75,6 \pm 10,7$ \\
\hline \multirow{15}{*}{ Post-inhalation observation } & \multirow{5}{*}{ Anthracite } & & $506.5 \pm 29.1 x$ & $2955.2 \pm 166.4 x$ & \multirow{2}{*}{$56,2 \pm 9,10$} \\
\hline & & Avitr & $\mathrm{P} \leq 0,01$ & $P \leq 0,001$ & \\
\hline & & \multirow{2}{*}{ Affusion } & $646.8 \pm 63.6 x$ & $3326.0 \pm 95.1 x$ & \multirow{2}{*}{$50,2 \pm 10,4$} \\
\hline & & & $\mathrm{P} \leq 0,01$ & $P \leq 0,001$ & \\
\hline & & Control & $387.8 \pm 23.9$ & $1954.0 \pm 110.6$ & $34,8 \pm 4,9$ \\
\hline & \multirow{5}{*}{ Stone coal } & \multirow{2}{*}{ KUner } & \multirow{2}{*}{$399.1 \pm 31.0$} & \multirow{2}{*}{$3531.4 \pm 291.3$} & $118.2 \pm 6.4 \mathrm{x}$ \\
\hline & & & & & $\mathrm{P} \leq 0.01$ \\
\hline & & \multirow{2}{*}{ Kukoks } & \multirow{2}{*}{$514.6 \pm 3.4 \times \mathrm{P} \leq 0.001$ Ro $\leq 0.05$} & $4321.0 \pm 218.3 x$ & $120.5 \pm 7.4 x$ \\
\hline & & & & $P \leq 0,001$ & $\mathrm{P} \leq 0.02$ \\
\hline & & Control & $335.6 \pm 19.6$ & $2822 \pm 176.4$ & $147.1 \pm 6.0$ \\
\hline & \multirow{5}{*}{ Brown coal } & \multirow{2}{*}{ Buckling } & $565.1 \pm 56.0 x$ & $3441.8 \pm 347.0 \mathrm{x}$ & \multirow{2}{*}{$199,2 \pm 9,2$} \\
\hline & & & $\mathrm{P} \leq 0,001$ & $\mathrm{P} \leq 0,01$ & \\
\hline & & \multirow{2}{*}{$\mathrm{U} \mathrm{fk}$} & $454.6 \pm 42.0 \mathrm{x}$ & $2983.8 \pm 555.1 x$ & \multirow{2}{*}{$204,0 \pm 13,1$} \\
\hline & & & $P \leq 0.01$ & $\mathrm{P} \leq 0.05$ & \\
\hline & & Control & $271.3 \pm 11.6$ & $1638.2 \pm 224.1$ & $231,7 \pm 22,2$ \\
\hline
\end{tabular}

Symbols: $\mathrm{X}$ - statistically significant differences with the control; $\mathrm{P} \leq$ is the confidence level.

\section{References}

1. Izmerov NF, Tkachev VV, Sobolev VV (1995) Calculation and regulation of dust exposure doses in order to reduce the level of occupational diseases of dust exposure. Labor Medicine and Industrial Ecology 5: C1-4.

2. Lutsenko LA (1998) Scientific bases of hygienic regulation of industrial dust of fossil coal of various material composition. Abstract of dissertation for the degree of Doctor of Medical Sciences. M 48c.

3. Velichkovsky BT (1980) Fibrogenic dust. Features of the structure and mechanism of biological action. Bitter, pp. 159.

4. Velichkovsky BT (1995) On the mechanism of the impact of fibrogenic dust on the body. Pulmonology 1: 6-16.

ISSN: 2574-1241

DOI: 10.26717/BJSTR.2019.16.002794

Lutsenko Lydia Alexandrovna. Biomed J Sci \& Tech Res

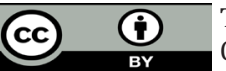

This work is licensed under Creative

Commons Attribution 4.0 License

Submission Link: https://biomedres.us/submit-manuscript.php
5. Dinkelis SS, Derr EA, Kukharenko TA (1981) The etiological role of coal in the development of pneumoconiosis. Healthcare of Kazakhstan 3: 4447.

6. Katsnelson BA, Babushkina LG (1968) About the importance of dust accumulation in the lymph nodes and the increase in their weight for the experimental assessment of the danger of various types of dust. Hygiene and sanitation 3(3): 108-110.

7. Ivanova LG (1997) Scientific substantiation of a complex cytomorphological approach to the hygienic assessment of coal dust Auth diss kand. Honey sciences M 25s. hygienic evaluation.

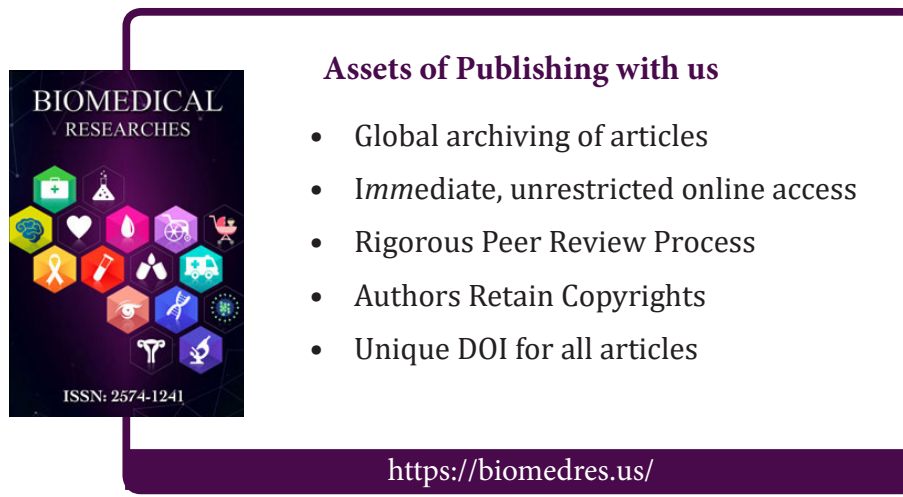

